\title{
Prevalence and risk factors of Type 2 diabetes in an urbanizing rural community of Bangladesh
}

\author{
Md. Mafuzar Rahman ${ }^{1}$, Md. Abdur Rahim ${ }^{1}$ and Quamrun Nahar $^{2}$ \\ ${ }^{1}$ Department of Community Medicine, National Institute of Preventive and Social Medicine, \\ Mohakhali, Dhaka 1212; ${ }^{2}$ ICDDR'B, Center for Health and Population Research, \\ Mohakhali, Dhaka 1212,Bangladesh.e-mail: rahim_md@hotail.com
}

\begin{abstract}
This cross-sectional study was carried out to estimate the prevalence of type 2 diabetes mellitus and its' risk factors in an urbanizing rural community of Bangladesh. Two villages were randomly selected from the rural areas of Gazipur district and total 975 subjects $(\geq 20$ years), were included following simple random procedure. Capillary blood glucose levels, fasting blood glucose (FBG) levels and 2hour after $75 \mathrm{~g}$ oral glucose load (OGTT) were measured. Height, weight, waist and hip circumferences and blood pressure were measured. The study population was lean with mean body mass index (BMI) of 20.48. The total prevalence of type 2 diabetes was $8.5 \%$, men showed higher prevalence $(9.4 \%)$ compare to women $(8.0 \%)$. Increasing age and higher BMI were found to be significant risk factors following both FBG and OGTT. The study has shown that prevalence of diabetes has increased in the populations who are in transitional stage of urbanization, and may indicate an epidemiological transition due to fast expanding urbanization.
\end{abstract}

\section{Introduction}

Type 2 diabetes mellitus poses a major global health threat, especially in the developed and developing countries ${ }^{1}$. The increasing trend of type 2 diabetes is common in the developing nations and most common in Southeast Asian countries ${ }^{1}$. Recent epidemiologi-cal studies have shown an increased prevalence of diabetes in India (11.6\%), Pakistan (11.1\%), Hawaii (20.4\%), and Turkey $(7.2 \%)^{2-5}$. It has been suggested that the increase in prevalence of diabetes among Asian Americans is due to ageing of the population, urbanization and increasing prevalence of obesity and physical inactivity ${ }^{6}$.

Some population based studies conducted in Bangladesh at different times have revealed an increasing trend of diabetes prevalence ranging from 1.0 to $3.8 \%$ in rural population and 1.5 to $8.0 \%$ in urban population ${ }^{7-9}$. Bangladeshis is more at risk to develop diabetes, hyperinsulinemia and coronary heart disease compared with other South Asian migrants settled in the $\mathrm{UK}^{10}$.

It was reported that prevalence of type 2 diabetes is on the rise more in urban areas compared to rural population in Bangladesh ${ }^{9,11}$. Bangladesh is one of the developing countries in the world, which is facing rapid urbanization in recent time $^{12}$. The country is also in the stage of demographic transition with an increasing proportion of older population. Urbaniza-tion was found to be associated with a sedentary lifestyle, higher calorie food intake and stressful condition, which might have contributed to the increasing prevalence of diabetes $^{1,}{ }^{13}$. Previously, 4-fold increase in prevalence of type 2 diabetes was noted among urban migrants compare to their source population (rural) without increased obesity or hypertension ${ }^{11}$. To the best of our knowledge there is no welldesigned study conducted to observe the prevalence of type 2 diabetes and its associated risk factors in the urbanizing rural population in Bangladesh.

We selected a rural area in Gazipur district. The area is now considered as semi-urban because there are some structural changes that have occurred in last five years like brick road communication, water supply, electricity and setting of water-seal latrines. In addition to these changes, some new industries also lay down up there. So, people of the areas now have some urban facilities with improving lifestyle from rural to semi-urban. Therefore, the purpose of the study was to observe the prevalence of type 2 diabetes and identify its' risk factors in an urbanizing rural population in Bangladesh. Moreover, the diagnostic procedures were largely based on fasting blood glucose (FBG) 
and/or 2-hour after $75 \mathrm{~g}$ oral glucose load (OGTT), therefore, risk estimates were performed and compared following both procedures.

\section{Materials and Methods}

The selected rural area is situated $50 \mathrm{~km}$ north of Dhaka city in Gazipur district. Two villages were randomly selected from the Gazipur district and from these two villages a census was done for the population of $\geq 20$ years and above from the household survey and approximately 2,000 populations, both male and female aged $\geq 20$ years, were registered from the census population. From those, 1,000 subjects were selected following a simple random sampling technique for investigating the prevalence of diabetes mellitus and other abnormal glucose conditions. Of them 25 subjects did not participate in the study, leaving 975 individuals for investigation and analysis.

Four days of training (both theoretical and field) for the project workers were conducted prior to the beginning of the field survey. The identification of population, census and numbering of the study subjects were made during the months of November-December 2004. FBG, biophysical examination and socio-demographic information were collected for the chosen 975 subjects during the months of January to March 2005.

Anthropometrics measurement for height, weight, hip and waist circumferences were taken. Weight was taken with light cloths and without shoes by a modern digital bathroom scale placed on a flat surface. The weighing machine was checked each day by a standard weight and the team members also checked their own weight as an additional daily check. The weight was recorded to the nearest $0.1 \mathrm{~kg}$. Height was measured without shoes, with the subjects standing fully erect on a flat surface. Heels, buttocks and shoulders should be flat on the measuring wall, which should be straight, and the subjects should look straight ahead (a line between the angle of eye and the upper point of attachment of ear should be horizontal). Fixing a tape measure to the wall and measuring the height with a movable headboard with a sufficient vertical dimension to ensure stability of the measuring wall. The headboard must be contact with the topmost point of the head with sufficient pressure to compress the hair and height was taken to the nearest centimeter.

Waist girth was measured by placing a plastic dressmaker's tape horizontally midway between the lower border of the ribs and iliac crest on the mid- axillary's line. The measurement was recorded at the nearest $\mathrm{cm}$. Hip circumference was measured to the nearest $\mathrm{cm}$ at the greatest protrusion of the buttocks and at the level of greater trochanter and symphysis pubis horizontally. Body mass index (BMI) was calculated as weight in $\mathrm{kg} /$ height in $\mathrm{m}^{2}$ and waist to hip ratio (WHR) was taken as waist/hip circumference.

Blood pressure (BP) was taken after administration of the questionnaire and finishing the anthropometrical measurements. To reduce the variation of BP the subject was ensured rest and relaxation at least 10 minutes in sitting position before BP was record. The pressure was measured on the right arm using normal cuffs for adults fitted with a standard mercury sphygmomanometer, placing the stethoscope bell lightly over the pulsatile brachial artery. Pressure was usually recorded to the nearest $2 \mathrm{~mm}$ $\mathrm{Hg}$ from the top of the mercury meniscus. Systolic pressure was recorded at the first appearance of sounds, and diastolic pressure was measured at phase $\mathrm{V}$, disappearance of sounds.

FBG from capillary whole blood was performed following the new WHO diagnostic criteria ${ }^{14}$. All the subjects were then given a $75 \mathrm{~g}$ oral glucose solution to drink for a 2-hour post glucose challenge test. For prevalence of diabetes, FBG of ADA criteria was used.

The ACCU-CHECK glucose machine was used in the field to estimate the blood glucose value. The machine was calibrated with a standard range of (control) reading prior to start estimation, and it was rechecked after every 20 patients.

Statistical analysis: Data were registered using Microsoft Access data entry. Control of data entry was secured through both program appliance and manually. The prevalence rate of diabetes was determined by simple percentage. Statistical comparisons between different groups were made using $\chi^{2}$ test. The odds ratio (OR) with $95 \%$ confidence interval (CI) for risk factors was calculated taking the least prevalence of complications or clinically relevant criteria as a reference value. All P-values presented are two-tailed. Multiple logistic regressions were executed to adjust for potential confounding factors; using SPSS 11.0 software performed all statistical analysis.

\section{Results}

Among the 975 participants, 31\% were males and $63 \%$ were females. Table I shows the selected characteristics of the study subjects. The majority of the subjects were young; however, the 
proportion of young among the males was lower than the females and the proportion that were older $(50+)$ were more among the males than females. Regarding educational status most of the subjects were literate and only a few were illiterate. Most of the male subjects were business-man and employed in different local industries and some other business farm. Among the males more than 50\% had monthly household income more than Tk. 5,000 and this figure was almost reverse among the females.

Table I: Selected socio-demographic characteristics of the sample populations

\begin{tabular}{lrrr}
\hline Characteristics & Male & Female & Total \\
\hline & $\mathrm{n}=360$ & $\mathrm{n}=615$ & $\mathrm{n}=975$ \\
\hline Age group in years & & & \\
\hline $20-30$ & 108 & 252 & 360 \\
$31-40$ & 94 & 177 & 271 \\
$41-50$ & 62 & 80 & 142 \\
50+ & 96 & 106 & 202 \\
Mean age & 41.7 & 37.3 & \\
\hline Education & & & \\
\hline Literate & 290 & 525 & 815 \\
Illiterate & 70 & 90 & 160 \\
\hline Occupation & & & \\
\hline Student & 80 & 40 & 120 \\
Service & 110 & 100 & 210 \\
Business & 120 & 35 & 155 \\
House wife & & 375 & 375 \\
Others & 50 & 65 & 115 \\
Monthly income in Taka & & & \\
\hline < 5,000 & 175 & 480 & 655 \\
> 5,000 & 185 & & 320 \\
\hline
\end{tabular}

Table II shows the differences of mean values with $\pm \mathrm{SD}$ and their $\mathrm{P}$ values between males and females for anthropometric and clinical characteristics. The mean age, height, weights, waist circumference, WHR were significantly higher $(\mathrm{p}<0.001)$ for males than the females and the mean values of 2-hour post glucose test were considerably higher among the females compare to males.

The prevalence of diabetes in males and females were $9.4 \%$ and $8.0 \%$ and the prevalence of impaired fasting glycaemia was 3.9\% and 5.2\% respectively following fasting blood glucose values. The higher prevalence of diabetes was found among the higher age group for both males and females. The male had higher prevalence of diabetes among the older subjects compare to fema les (Table III). The prevalence of impaired glucose tolerance increased consistently with increasing age
Table II: Mean values (SD) for anthropometric and clinical variables of the study subjects

\begin{tabular}{|c|c|c|c|}
\hline Variables & $\begin{array}{c}\text { Male } \\
(n=360) \\
\text { Mean (SD) }\end{array}$ & $\begin{array}{c}\text { Female } \\
(n=615) \\
\text { Mean }(\mathrm{SD})\end{array}$ & $\mathrm{P}$ value \\
\hline \multicolumn{4}{|l|}{$\begin{array}{l}\text { Anthropometric } \\
\text { variables }\end{array}$} \\
\hline Height in $\mathrm{cm}$ & $161.74(6.89)$ & $150.74(6.24)$ & 0.00 \\
\hline Weight in $\mathrm{kg}$ & $53.74(9.90)$ & $46.58(8.57)$ & 0.00 \\
\hline $\begin{array}{l}\text { Waist } \\
\text { circumference in } \\
\mathrm{cm}\end{array}$ & $74.81(9.35)$ & $71.88(9.52)$ & 0.00 \\
\hline $\begin{array}{l}\text { Body mass index } \\
(\mathrm{BMI}), \mathrm{wt} \text { in } \mathrm{kg} / \mathrm{ht} \mathrm{m}^{2}\end{array}$ & $20.48(3.20)$ & $20.48(3.44)$ & 0.97 \\
\hline $\begin{array}{l}\text { Waist to hip ratio } \\
\text { (WHR) }\end{array}$ & $0.88(0.06$ & $0.84(0.06)$ & 0.00 \\
\hline \multicolumn{4}{|l|}{ Clinical variables } \\
\hline $\begin{array}{l}\text { Systolic blood } \\
\text { pressure (mm Hg) }\end{array}$ & $120.14(19.77)$ & $119.99(18.75)$ & 0.90 \\
\hline $\begin{array}{l}\text { Diastolic blood } \\
\text { pressure (mm Hg) }\end{array}$ & $77.39(11.81)$ & $77.40(11.56)$ & 0.99 \\
\hline $\begin{array}{l}\text { Fasting blood glucose } \\
(\mathrm{FBG}) \mathrm{mmol} / \mathrm{l}\end{array}$ & $5.02(3.29)$ & $4.91(1.38)$ & 0.52 \\
\hline $\begin{array}{l}\text { 2-hour post glucose } \\
\text { test (OGTT) } \\
\mathrm{mmol} / \mathrm{l}\end{array}$ & $5.71(3.12)$ & $6.10(2.88)$ & 0.05 \\
\hline
\end{tabular}

among the females. The total prevalence of diabetes in males is slightly higher than females although the increased prevalence of impaired glucose tolerance was noted among the females compared to male subjects following OGTT (Table III).

The prevalence of diabetes was higher following FBG criterion $(8.5 \%)$ than the OGTT $(4.9 \%)$. The prevalence of diabetes among the males and females was also higher following FBG values compared to OGTT values. Group comparisons were done by using $\mathrm{X}^{2}$ test. Age and higher BMI $\geq 25.00$ were statistically significant for the development of diabetes following FBG and OGTT in multivariate analysis after adjusting for a number of other potential confounders. The risk for diabetes is higher in age strata $31-40$ years by FBG and OGTT compare to younger and older age group (Table IV). We did not find any significant association between systolic and diastolic hypertension and central obesity for the occurrence of diabetes in multivariate analysis, whereas the association was apparent in bivariate model.

\section{Discussion}

In this study we observed that female participation was almost two times higher than male. In rural Bangladesh male population mostly engaged in agriculture work, outside business and other out-of- 
Table III: Prevalence of diabetes and other abnormal glucose conditions following fasting blood glucose and 2-hour post glucose test by age and sex

\begin{tabular}{|c|c|c|c|c|}
\hline \multirow[t]{2}{*}{ Age group } & \multicolumn{2}{|c|}{ Fasting blood glucose } & \multicolumn{2}{|c|}{ 2-hour post glucose test } \\
\hline & $\begin{array}{c}\text { Prevalence in diabetes } \\
\qquad(95 \% \mathrm{CI})\end{array}$ & $\begin{array}{l}\text { Prevalence in impaired } \\
\text { fasting glucose }(95 \% \mathrm{CI})\end{array}$ & $\begin{array}{c}\text { Prevalence in diabetes } \\
\qquad(95 \% \mathrm{CI})\end{array}$ & $\begin{array}{l}\text { Prevalence in impaired } \\
\text { fasting glucose }(95 \% \mathrm{CI})\end{array}$ \\
\hline \multicolumn{5}{|l|}{ Male } \\
\hline $20-30$ & $2.8(0.5-7.9)$ & $2.8(0.6-7.9)$ & $1.9(0.2-6.5)$ & $3.7(1.0-9.2)$ \\
\hline $31-40$ & $8.5(3.7-16.1)$ & $2.1(0.3-7.5)$ & $6.4(2.4-13.4)$ & $7.4(3.0-14.7)$ \\
\hline $41-50$ & $8.1(2.7-17.8)$ & $3.2(0.4-11.2)$ & $6.5(1.8-15.7)$ & $3.2(0.4-11.2)$ \\
\hline $51->$ & $18.8(11.5-28.0)$ & $7.3(3.0-14.4)$ & $9.4(4.4-17.1)$ & $11.5(5.9-19.6)$ \\
\hline Total & $9.4(6.6-12.9)$ & $3.9(2.1-6.4)$ & $5.8(3.6-8.8)$ & $6.7(4.3-9.8)$ \\
\hline \multicolumn{5}{|l|}{ Female } \\
\hline $20-30$ & $3.6(1.6-6.7)$ & $3.6(1.6-6.7)$ & $0.8(0.1-2.8)$ & $7.5(4.6-11.5)$ \\
\hline $31-40$ & $13.0(8.4-18.9)$ & $3.4(1.3-7.2)$ & $8.5(4.8-13.6)$ & $6.8(3.6-11.5)$ \\
\hline $41-50$ & $7.5(2.8-15.6)$ & $5.0(1.4-12.3)$ & $3.8(0.8-10.6)$ & $12.5(6.2-21.8)$ \\
\hline $51->$ & $10.4(5.3-17.8)$ & $12.3(6.7-20.1)$ & $6.6(2.7-13.1)$ & $17.9(11.2-26.6)$ \\
\hline Total & $8.0(6.0-10.4)$ & $5.2(3.6-7.3)$ & $4.4(2.9-6.3)$ & $9.8(7.5-12.4)$ \\
\hline
\end{tabular}

Table IV: Odds ratio (OR) with $95 \%$ CI of diabetes following fasting blood glucose values and 2-hour post glucose values by the following risk factors in urbanizing rural population of Bangladesh

\begin{tabular}{|c|c|c|c|c|c|c|}
\hline \multirow[b]{2}{*}{ Variables } & \multicolumn{3}{|c|}{ Fasting blood glucose } & \multicolumn{3}{|c|}{ 2-hour post glucose test } \\
\hline & $\mathrm{n}$ & $\mathrm{OR}^{*}$ & $95 \% \mathrm{CI}$ & $\mathrm{n}$ & OR & $95 \% \mathrm{CI}$ \\
\hline \multicolumn{7}{|l|}{ Age } \\
\hline $20-30$ & 360 & 1.0 & & 360 & 1.0 & \\
\hline $31-40$ & 271 & 3.3 & $1.6-6.7$ & 271 & 6.4 & $2.1-19.2$ \\
\hline $41-50$ & 142 & 2.0 & $0.8-4.9$ & 142 & 3.8 & $1.0-13.4$ \\
\hline $51->$ & 202 & 4.0 & $1.8-8.5$ & 202 & 6.4 & $2.0-20.7$ \\
\hline \multicolumn{7}{|l|}{ Sex } \\
\hline Male & 360 & 1.0 & & 360 & 1.0 & \\
\hline Female & 615 & 0.8 & $0.5-1.4$ & 615 & 0.7 & $0.3-1.3$ \\
\hline \multicolumn{7}{|l|}{ BMI } \\
\hline$>18.5$ & 285 & 1.0 & & 285 & 1.0 & \\
\hline $18.5-24.9$ & 590 & 1.4 & $0.7-2.6$ & 590 & 1.9 & $0.9-4.1$ \\
\hline $25.0->$ & 100 & 2.5 & $1.3-4.9$ & 100 & 3.3 & $1.4-7.3$ \\
\hline \multicolumn{7}{|l|}{ Systolic BP } \\
\hline$=140 \mathrm{mmHg}$ & 884 & 1.0 & & 884 & 1.0 & \\
\hline$>140 \mathrm{mmHg}$ & 91 & 1.5 & $0.5-4.2$ & 91 & 2.5 & $0.7-9.0$ \\
\hline \multicolumn{7}{|l|}{ Diastolic BP } \\
\hline$=90 \mathrm{mmHg}$ & 890 & 1.0 & & 890 & 1.0 & \\
\hline$>90 \mathrm{mmHg}$ & 85 & 1.2 & $0.4-3.4$ & 85 & 0.5 & $0.1-2.1$ \\
\hline \multicolumn{7}{|l|}{ Central obesity } \\
\hline Absent & 389 & 1.0 & & 389 & 1.0 & \\
\hline Present & 586 & 1.2 & $0.6-2.1$ & 586 & 1.5 & $0.6-3.2$ \\
\hline
\end{tabular}

*OR, adjusted odds ratio for age, sex, systolic BP, diastolic BP, and BMI and for central obesity for the rural population; BMI, body mass index was calculated as weight in $\mathrm{kg}$ / height in $\mathrm{m}^{2}$; Central obesity was defined as (WHR $>0.9$ for male and or WHR $>0.8$ for female)

home works and during the study period males' involvement was lower than women at the invest- tigation site. In other studies in Bangladesh especially on rural areas showed the female 
preponderance of participation for diabetes investigation $^{15}$. Our populations are comparatively younger both male and female, and female were younger than males. The mean age in the study subjects are consistent with the national population mean age in Bangladesh.

We have observed a higher prevalence (8.5\%) of type 2 diabetes among the rural subjects. We have found the higher prevalence of diabetes among the males $(9.4 \%)$ compare to females $(8.0 \%)$ but the differences were not statistically significant. This prevalence rate in the rural population is noticeably higher than in the previous studies in Bangladesh ${ }^{16}$, 17. It is also higher than the rural prevalence of China $(2.5 \%)$, Mongolia $(2.9 \%)$ and India $(2.4 \%)^{18-}$ 20

The recent report of urban Indians showed that there was $40 \%$ increase in type 2 diabetes from $8.2 \%$ in 1988 to $11.6 \%$ in $1995^{2}$. Urban studies in Bangladesh have also shown increasing prevalence of diabetes in $1996(7.9 \%)$ and in $2000(8.1 \%)^{8}$, ${ }^{11}$.This may suggest that the observed results are in feared concordance with other studies in India ${ }^{20,} 2$ and Bangladesh ${ }^{8}$.

The present study showed the higher prevalence of diabetes among the younger women in age strata 20-40 years compared to male subjects. The findings of the female predominance at younger age are inconsistent with the previous study conducted in Bangladesh ${ }^{8}$.

The prevalence of impaired fasting glucose is lower than diabetes for both men and women following FBG, but the prevalence of impaired glucose tolerance is significantly higher than diabetes following OGTT. Impaired glucose tolerance is the peripatetic condition and it appears 5-10 years before the diagnosis of diabetes is established. The increased impaired glucose tolerance is an emerging thread for the rural population for developing diabetes in coming decades. In our population impaired glucose tolerance is the index of pre-diabetic condition than impaired fasting glucose but in American and Europeans population impaired fasting glucose is more applicable for assessing the pre diabetic state. So in lean population like Indians and Bangladeshis, OGTT may vary the number of diabetic population than FBG.

We found systolic and diastolic hypertension was associated with the prevalence of diabetes in the bivariate analysis (data not shown), but in multivariate analysis the association was not apparent. Systolic and diastolic hypertension was found to be significantly associated with higher FBG levels in a previous rural study ${ }^{8,11}$. Significant association was found with hypertension and type 2 diabetes in Turkey, ${ }^{5}$, Japanese Americans ${ }^{21}$ and among the Polynesians in Tonga ${ }^{22}$. Systolic hypertension was found to be associated with the prevalence of diabetes in southern Taiwan ${ }^{23}$, in Nigeria $^{24}$ and in China ${ }^{25}$.

Obesity is an established risk factor for type 2 diabetes, we found a significant association between higher BMI $>25.00$ and occurrence of diabetes in our survey. Data from previous studies showed a marginal risk for type 2 diabetes with higher BMI for both sexes in Bangladesh ${ }^{26}$. An Indian study has also shown that higher BMI is independently associated as risk for the occurrence of type 2 diabetes among men and women ${ }^{2}$.

Central obesity (waist-to-hip ratio) was significantly associated with the occurrence of diabetes in men and women. The association between WHR and diabetes was also evident in previous studies in Bangladesh $^{11}$. Studies on South Asians migrants also showed that the WHR was higher among the migrants than the European populations of the same $\mathrm{BMI}^{27}$. South Asians, especially Indians and Bangladeshi population represents a particular form of physical structure, usually a deposition of fat in the central abdominal region other than extremities. It is postulated that we are representing a distinctive form of type 2 diabetes among a lean population, related to diabetes described in Indian population $^{28}$.

In multivariate analysis, higher age and higher BMI was significantly associated for the development of diabetes in our population but in bivariate model the central obesity and hypertension showed significant association.

The higher prevalence in the present report is not likely to be the true prevalence of diabetes in rural population of Bangladesh. The study area was selected purposively as a rural, $50 \mathrm{~km}$ far from Dhaka to and the sample size was not so large as to represent the real picture of the country burden of diabetes.

In conclusion, the higher prevalence in the present study indicates the environmental factors may encompass a strong role for the rising prevalence of diabetes in urbanizing population in a developing country like Bangladesh. FBG showed higher prevalence compare to OGTT in our population. In this context we can say FBG is suitable diagnostic tools for diagnosis of diabetes in epidemiological study rather than OGTT. 


\section{Acknowledgements}

We acknowledge the contribution of our survey team members, the village leaders and volunteers for their continuous effort in the collection of data. We express our thanks to the WHO Office Dhaka, Bangladesh for providing financial support to accomplish the project work. We are also grateful to all participants in the study for their active co-operation.

\section{Authors' contribution}

MMR: Designed the study, supervised field survey and reviewed the draft manuscript.

MAR: Designed the study, recruitment of the study subjects, collected data and entered and analyzed, and wrote the manuscript. QN: Data analysis and interpretation of results and reviewed the draft manuscript.

\section{References}

1 Wild H, Roglic G, Green A, Sicree R, King H. Global prevalence of diabetes, estimates for the year 2000 and projections for 2030. Diabetes Care 2004; 27: 1047 53

2 Ramachandran A, Snehalatha C, Latha E, Vijay V, Vishanathan M. Rising prevalence of NIDDM in an urban population in India. Diabetologia 1997; 40: 23237

3 Shera AS, Rafique G, Khwaja IA, Baqai S, Khan IA, King $\mathrm{H}$, Ahmed KI. Pakistan National Diabetes Survey prevalence of glucose intolerance and associated factors in North West at Frontier Province (NWFP) of Pakistan. J Pak Med Assoc. 1999; 49: 20611.

4 Grandinetti A, Chang HK, Mau MK, Curb JD, Kenny EK, Sagum R, Arakaki RF. Prevalence of glucose intolerance among Native Hawaiians in two rural communities. Native Hawaiian Health Research (NHHR) Project. Diabetes Care 1998; 21: 549-54.

5 Satman I, Yilmaz T, Sengul A, Salman S, Salman F, Uygur S, Baster I, Tutuncu Y, Sargin M, Dinccag N, Karsidag K, Kalaca S, Ozcan C, King H. Populationbased study of diabetes and risk characteristics in Turkey: Results of the Turkish Diabetes Epidemiology Study (TURDEP). Diabetes Care 2002; 25: 1515-56.

6 Marguerite J, McNeely, Edward J. Type 2 diabetes prevalence in Asian Americans. Diabetes Care 2004; 27: 66-69.

7 Sayeed MA, Hossain MZ, Banu A, Rumi MAK, Azad Khan AK. Prevalence of diabetes in a suburban population of Bangladesh. Diabet Res Clin Pract. 1997; 34: 149-55.

8 Sayeed MA, Hussain MZ, Banu A, Ali L, Rumi MAK, Azad Khan AK. Effect of socio-economic risk factors on difference between rural and urban in the prevalence of diabetes in Bangladesh. Diabetes Care 1997; 20: 551-55.

9 Sayeed MA, Mahtab H, Khanum PA, Latif ZA, Ali SMK, Banu A et al. Diabetes and Impaired fasting glycaemia in rural population of Bangladesh. Diabetes Care 2003; 26: 1034-103.
10 McKeigue PM, Miller GJ, Marmot MG. Coronary heart disease in south Asian overseas- A review. J Clin Epidemiol. 1989; 42: 597-609.

11 Hussain A, Rahim MA, Azad Khan AK, Ali SMK. Type 2 diabetes in rural and urban population: Diverse prevalence and associated risk factors in Bangladesh. Diabet Med. 2005; 22: 931-37.

12 Laskar SI. Urbanization in Bangladesh: Some contemporary observations. Bangladesh Dev Stud. 1996; 24: 207-16.

13 Ramachandran A, Snehalatha C, Latha E, Vijay V, Vishanathan M. Impacts of urbanization on life style and on the prevalence of diabetes in native Asian Indian population. Diabet Res Clin Pract. 1999; 44 : 207-13.

14 The Expert Committee on the diagnosis and classification of diabetes mellitus. Report of the expert committee on the diagnosis and classification of diabetes mellitus. Diabetes Care 1997; 20:1183-97.

15 Sayeed MA, Mahtab H, Khanum PA, Latif ZA, Ali SMK, Banu A. Diabetes and impaired fasting glycaemia in rural population of Bangladesh. Diabetes Care 2003; 26: 1034-39.

16 Sayeed MA, Khan AR, Banu A, Hussain MZ. Prevalence of diabetes and hypertension in a rural population of Bangladesh. Diabetes Care 1995; 18: $555-58$.

17 Sayeed MA, Hossain MZ, Banu A, Rumi MAK, Azad Khan AK. Prevalence of diabetes in a suburban population of Bangladesh. Diabet Res Clin Pract. 1997; 34: 149-55.

18 Pan XR, Yang WY, Li GW, Liu J. Prevalence of diabetes and its risk factors in Chaina, 1994. National Diabetes Prevention and Control Cooperative Group. Diabetes Care 1997; 20: 1664-69.

19 Suvd J, Gerel B, Otogooloi H, Purevsuren D, Zolazaya $\mathrm{H}$, Roglic G, King H. Glucose intolerance and associated factors in Mongolia: Results of a national survey. Diabet Med. 2002; 19: 502-08.

20 Ramachandran A, Snehalatha C, Dharmaraj D, Viswanathan M. Prevalence of glucose intolerance in Asian Indians. Diabetes Care 1992; 15: 1348-55.

21 Liao D, Shoffer BJ, Boyko EJ, McNeely JM, Leonetti LD. Abnormal glucose tolerance and increased risk for cardiovascular disease in Japanese-Americans with normal fasting glucose. Diabetes Care 2001; 24: 3944.

22 Collgiuri S, Collgiuri R, Naati S, Muimuiheata S, Hussain Z, Palu T. The prevalence of diabetes in the kingdom of Tonga. Diabetes Care 2002; 25: 1378-83.

23 Lu FH, Yang YC, Wu JS, Wu CH, Chang CJ. A population based study of the prevalence and associated factors of diabetes mellitus in southern Taiwan. Diabet Med. 1998; 15: 564-72.

24 Olatunbosun ST, Ojo PO, Fineberg NS, Bella F. Prevalence of diabetes mellitus and impaired glucose 
tolerance in a group of urban adults in Nigeria. J Nat Med Assoc. 1998; 90: 293-301.

25 Pan XR, Yang WY, Li GW, Liu J. Prevalence of diabetes and its risk factors in China, 1994. National Diabetes Prevention and Control Cooperative Group. Diabetes Care 1997; 20: 1664-69.

26 Sayeed MA, Banu A, Malek MA, Azad Khan AK. Blood pressure and coronary heart disease in NIDDM subjects at diagnosis: Prevalence and risks in a
Bangladeshi population. Diabet Res Clin Pract. 1998; 39: $147-55$.

27 Zimmet P. The epidemiology of diabetes mellitus and associated disorders. In: Alberti KGMM, Kral LP (eds) The diabetes Annals- 6. Amsterdam, Elsevier Science, 1991, pp 1-19.

28 Ramaiya KL, Kodali VRR, Alberti KGMM. Epidemiology of diabetes in Asians of Indian subcontinent. Diabet Metab Rev. 1990; 6: 125-46. 